\title{
Effects of various acute hypoxic conditions on metabolic parameters and cardiac function during exercise and recovery
}

Hwang-woon Moon', Sub Sunoo ${ }^{2}$, Hun-young Park ${ }^{3}$, Dong-jun Lee ${ }^{4}$ and Sang-seok Nam²*

\begin{abstract}
Purpose: Evaluation of metabolic parameters and cardiac function is important to determine the decrease in aerobic exercise capacity under hypoxic conditions. However, the variations in metabolic parameters and cardiac function and the reasons for the decrease in aerobic exercise capacity under hypoxic conditions have not been clearly explained. The purpose of this study was to compare the responses between sea level and various acute normobaric hypoxic conditions on metabolic parameters and cardiac function during exercise and recovery in order to evaluate aerobic exercise capacity.

Methods: Ten healthy male participants $(21.3 \pm 3.06 \mathrm{y})$ performed submaximal bicycle exercise $(116.7 \pm 20.1 \mathrm{~W}$ and $60 \mathrm{rpm})$ at sea level $\left(20.9 \% \mathrm{O}_{2}\right)$ and under various normobaric hypoxic conditions $\left(16.5 \% \mathrm{O}_{2}, 14.5 \% \mathrm{O}_{2}, 12.8 \% \mathrm{O}_{2}\right.$, and $11.2 \% \mathrm{O}_{2}$ ) in a random order. Metabolic parameters (arterial oxygen saturation; $\mathrm{S}_{\mathrm{p}} \mathrm{O}_{2}$, oxygen consumption; $\mathrm{VO}_{2}$, blood lactate level) and cardiac function (heart rate; HR, stroke volume; SV, end-systolic volume; ESV, end-diastolic volume; EDV, ejection fraction; EF, cardiac output; $\mathrm{CO}$ ) were measured at rest, during exercise (30 min), and recovery (30 $\mathrm{min}$ ). We compared the responses on metabolic parameters and cardiac function between the different oxygen partial pressure conditions during exercise and recovery.

Results: The various acute normobaric hypoxic conditions did not affect $\mathrm{VO}_{2}$ and $\mathrm{SV}$ during exercise and recovery. $\mathrm{S}_{\mathrm{p}} \mathrm{O}_{2}$ decreased $(p<.05)$ and blood lactate level increased $(p<.05)$ as the oxygen partial pressure decreased. $\mathrm{HR}, \mathrm{EF}$, CO increased $(p<.05)$ and EDV, ESV decreased $(p<.05)$ at oxygen partial pressures of $14.5 \% \mathrm{O}_{2}$ and below compared with 20.9 and $16.5 \% \mathrm{O}_{2}$ during exercise and recovery.

Conclusion: A decrease in the oxygen partial pressure to $14.5 \% \mathrm{O}_{2}$ and below might be associated with significant changes in metabolic parameters and cardiac function during exercise and recovery. These changes are an acute compensation response to reduced aerobic exercise capacity by decreased oxygen delivering and utilizing capacities under hypoxic conditions.
\end{abstract}

Keywords: Normobaric hypoxic condition, Oxygen partial pressure, Metabolic parameters, Cardiac function, Aerobic exercise capacity

\section{Background}

In 1968, the Olympic Games were held at high altitude in Mexico City, and since then, the effects of hypoxic conditions at high altitude on exercise performance have

\footnotetext{
*Correspondence: captain@khu.ac.kr

${ }^{2}$ Department of Sports Medicine, Kyunghee University, 1732,

Deogyeong-daero, Giheung-gu, Yongin-si, Gyeonggi-do 17104, Republic of Korea

Full list of author information is available at the end of the article
}

received considerable attention (Morton and Cable 2005; Hinckson et al. 2006).

Under hypoxic conditions, oxygen partial pressure decreases owing to low atmospheric pressure, and this results in the reduction of the alveolar oxygen partial pressure, arterial blood oxygen saturation $\left(\mathrm{S}_{\mathrm{p}} \mathrm{O}_{2}\right)$, and arteriovenous oxygen difference, diminishing the capacity for oxygen delivery and utilization (Bhaumik et al. 2008; Brutsaert 2008). Compared with sea level (normoxia), 
submaximal exercise at the same intensity in hypoxic condition causes increase in ventilation, heart rate (HR), cardiac output (CO), blood lactate levels, and oxygen consumption $\left(\mathrm{VO}_{2}\right)$ due to decrease in oxygen delivering and utilizing capacity of the blood (Mazzeo et al. 1991; Welsman et al. 2005). In addition, maximal oxygen consumption $\left(\mathrm{VO}_{2} \mathrm{max}\right)$ and maximal power output are reduced in hypoxic conditions compared with sea level (Lawler et al. 1988; Robergs et al. 1998). Therefore, these results may shed light on metabolic parameters and cardiac function to response to various hypoxic conditions during exercise. Previous studies investigated the decrease in aerobic exercise capacity (e.g. $\mathrm{HR}, \mathrm{SpO}_{2}$, minute ventilation, red blood cell; RBC count, hemoglobin; $\mathrm{Hb}$ level, hematocrit; Hct, and $\mathrm{VO}_{2}$ ) under hypoxic conditions during submaximal exercise and $\mathrm{VO}_{2} \max$ (Lawler et al. 1988; Calbet et al. 2003; Friedmann et al. 2007; Bhaumik et al. 2008). However, very few studies conducted the effect of acute hypoxia on cardiac function. Most previous studies reported that acute exposure to hypoxic conditions activates the sympathetic nervous system and increases $H R$ (Hainsworth and Drinkhill 2007; Yan et al. 2007; Fukuda et al. 2010). However, results have been inconsistent regarding stroke volume (SV), end-systolic volume (ESV), end-diastolic volume (EDV), ejection fraction (EF), systemic vascular resistance (SVR), and CO (Thomson et al. 2006; Hsu et al. 2006; Hainsworth and Drinkhill 2007; Yan et al. 2007; Fukuda et al. 2010). These inconsistencies might have resulted from differences in the study design, extent of hypoxia, exercise type, intensity, and duration (Thomson et al. 2006; Lawler et al. 1988; Sunoo et al. 1997; Morton and Cable 2005; Hinckson et al. 2006; Friedmann et al. 2007; Adamos et al. 2008; Elstad et al. 2009). Therefore, variations in metabolic parameters and cardiac function, and decrease in aerobic exercise capacity under hypoxic conditions have not been explained clearly.

The present study was conducted to clarify the effects of acute normobaric hypoxic conditions on metabolic parameters and cardiac function during exercise and recovery in order to evaluate change on aerobic exercise capacity according to various hypoxic conditions.

\section{Methods}

\section{Participants}

The present study included 10 healthy college males who did not participate in any planned exercise program and did not consume any dietary supplements in the previous 6 months. The participants were non-smokers, and did not have any history of musculoskeletal, cardiovascular, or pulmonary disease. They received information about the purpose and process of this study, and provided informed consent prior to the start of the study. Characteristics of the participants are presented in Table 1 . This study was approved by the Institutional Review Board of Kyung Hee University (KHSIRB 2015-020) in Korea and was conducted according to the declaration of Helsinki.

\section{Experimental design}

All participants performed a physical work capacity (PWC) test at $70 \%$ HRmax to determine their bicycle exercise intensity at sea-level $\left(20.9 \% \mathrm{O}_{2}\right)$ and HRmax was determined using the predicted HRmax formula $($ Male $=206-0.69 \times$ age, Miyashita et al. 1985). The Aerobike 75XL II (Combi Corporation, Tokyo, Japan) was used to measure PWC $70 \%$ HRmax. All participants performed submaximal exercise at $116.7 \pm 20.1 \mathrm{~W}$ and maintained $60 \mathrm{rpm}$ during $30 \mathrm{~min}$ exercise at sea level $\left(20.9 \% \mathrm{O}_{2}\right)$ and various normobaric hypoxic conditions $\left(16.5 \% \mathrm{O}_{2}, 14.5 \% \mathrm{O}_{2}, 12.8 \% \mathrm{O}_{2}\right.$, and $\left.11.2 \% \mathrm{O}_{2}\right)$ in a random order. Right after exercise, participants were held still on a bicycle for 30 min during recovery. The variables were measured at rest, during exercise (30 $\mathrm{min})$, and recovery (30 min post exercise) at sea level and various normobaric hypoxic conditions.

The exercise performed in a $6.5 \times 7.5 \times 3$ m environmental chamber (Submersible Systems, Huntington Beach, CA) for all the conditions. The various normobaric hypoxic conditions simulated by introducing nitrogen into the environmental chamber, using a nitrogen generator (Separation \& Filter Energy Technology Cooperation, Siheung, Korea) with the capacity to simulate normobaric hypoxic conditions for altitudes of up to $9.7 \% \mathrm{O}_{2}$ $(6000 \mathrm{~m})$. The temperature and humidity within the environmental chamber were maintained at $20 \pm 2{ }^{\circ} \mathrm{C}$ and $60 \pm 2 \%$ for all the conditions, respectively. Each participant performed the bicycle exercise at sea level and various normobaric hypoxic conditions, and a minimum interval of 7 days was ensured between conditions.

\section{Cardiometabolic measurements}

The index finger of each participants were placed on the $\mathrm{S}_{\mathrm{p}} \mathrm{O}_{2}$ sensor of a radical-7 pulse oximeter (Masimo Corporation, Irvine, CA) to measure $\mathrm{S}_{\mathrm{p}} \mathrm{O}_{2}$. The Vmax229, breath-by-breath automatic metabolism analyzer (SensorMedics, Yorba Linda, CA) and a breathing valve in the form of a facemask used to measure $\mathrm{VO}_{2}$ at rest,

Table 1 Characteristic of participants

\begin{tabular}{llll}
\hline Variables & $\begin{array}{l}\text { Descriptive } \\
\text { statistics }\end{array}$ & Variables & $\begin{array}{l}\text { Descriptive } \\
\text { statistics }\end{array}$ \\
\hline Number $(\mathrm{n})$ & 10 & Fat free mass $(\mathrm{kg})$ & $35.5 \pm 4.41$ \\
Age (years) & $21.3 \pm 3.06$ & Fat mass $(\mathrm{kg})$ & $11.3 \pm 5.04$ \\
Height $(\mathrm{cm})$ & $176.9 \pm 4.38$ & Body mass index $\left(\mathrm{kg} / \mathrm{m}^{2}\right)$ & $22.5 \pm 2.40$ \\
Weight $(\mathrm{kg})$ & $70.8 \pm 9.68$ & Body fat $(\%)$ & $15.5 \pm 4.98$ \\
\hline
\end{tabular}


during exercise, and recovery under all the hypoxic conditions. For measuring the blood lactate level, we collected $80 \mu \mathrm{L}$ of blood in a capillary tube using the fingertip method, and the sample analyzed using the YSI1500 lactate analyzer (YSI Inc., Yellow Springs, OH). Cardiac function parameters, including the HR, SV, EDV, ESV, EF, and CO were assessed noninvasively by using a thoracic bioelectrical impedance device (PhysioFlow PF-05 Lab1, Manatec Biomedical, Paris, France), which has been previously shown to provide reliable results in healthy men and patients with chronic pulmonary disease (Charloux et al. 2000; Fukuda et al. 2010). The electrodes positioned on the forehead, neck, xiphoid process, and lower ribs on the left side, avoiding the abdominal muscles, as these positions were suggested to be appropriate for human participants (Charloux et al. 2000; Fukuda et al. 2010).

\section{Statistical analysis}

All data are presented as means \pm standard deviations. Two-way repeated analysis of variance (ANOVA) was used to figure out the interaction effects between condition and time at rest, during exercise, and recovery. Repeated oneway ANOVA was used to evaluate differences in dependent variables between all the conditions at each time point and post hoc test was used LSD (least significant difference). All statistical analyses were performed using SPSS version 22.0 (IBM Corp., Armonk, NY) for Windows. The level of significance was set at $p<.05$.

\section{Results}

There were some changes in metabolic parameters and cardiac function at rest, during exercise, and recovery as it is shown in Figs. 1 and 2.

\section{Metabolic parameters}

As shown in Fig. 1, there were interaction effects between condition and time on $\mathrm{S}_{\mathrm{p}} \mathrm{O}_{2}(\mathrm{~F}=3.590, p=.027$, panel a) and blood lactate level ( $\mathrm{F}=25.034, p<.000$, panel c). $\mathrm{S}_{\mathrm{P}} \mathrm{O}_{2}$ decreased $(p<.05)$ as the oxygen partial pressure decreased at rest, during exercise, and recovery. Blood lactate level increased at $16.5 \% \mathrm{O}_{2}, 14.5 \% \mathrm{O}_{2}, 12.8 \% \mathrm{O}_{2}$, and $11.2 \% \mathrm{O}_{2}(p<.05)$ compared with $20.9 \% \mathrm{O}_{2}$ during exercise and recovery, and it was increased at $11.2 \% \mathrm{O}_{2}$ $(p<.05)$ compared with all other oxygen levels. However, there was no difference in $\mathrm{VO}_{2}$ between all the conditions.

\section{Cardiac function}

As shown in Fig. 2, there were interaction effects between condition and time on HR $(\mathrm{F}=5.598, p<.000$, panel a) and $\mathrm{CO}(\mathrm{F}=2.668, p=.013$, panel $\mathrm{f})$. $\mathrm{HR}$ and $\mathrm{CO}$ increased in the oxygen partial pressure to $14.5 \% \mathrm{O}_{2}$ and below $(p<.05)$ compared with $20.9 \% \mathrm{O}_{2}$ during exercise and recovery (panels a and f) but SV showed no changes between all the conditions (panel b). EDV and ESV decreased at $12.8 \% \mathrm{O}_{2}$, and $11.2 \% \mathrm{O}_{2}(p<.05)$ compared with $20.9 \% \mathrm{O}_{2}$ during exercise (panels $\mathrm{c}$ and $\mathrm{d}$ ). EF increased in the oxygen partial pressure to $14.5 \% \mathrm{O}_{2}$ and below $(p<.05)$ compared with $20.9 \% \mathrm{O}_{2}$ during exercise and recovery (panel e).

\section{Discussion}

The present study was conducted to investigate the responses between various acute normobaric hypoxic conditions on metabolic parameters and cardiac function during exercise and recovery in order to evaluate aerobic exercise capacity. Our findings indicate that $\mathrm{S}_{\mathrm{P}} \mathrm{O}_{2}$ decreased $(\mathrm{p}<.05)$ and blood lactate level increased $(\mathrm{p}<.05)$ as the oxygen partial pressure decreased but
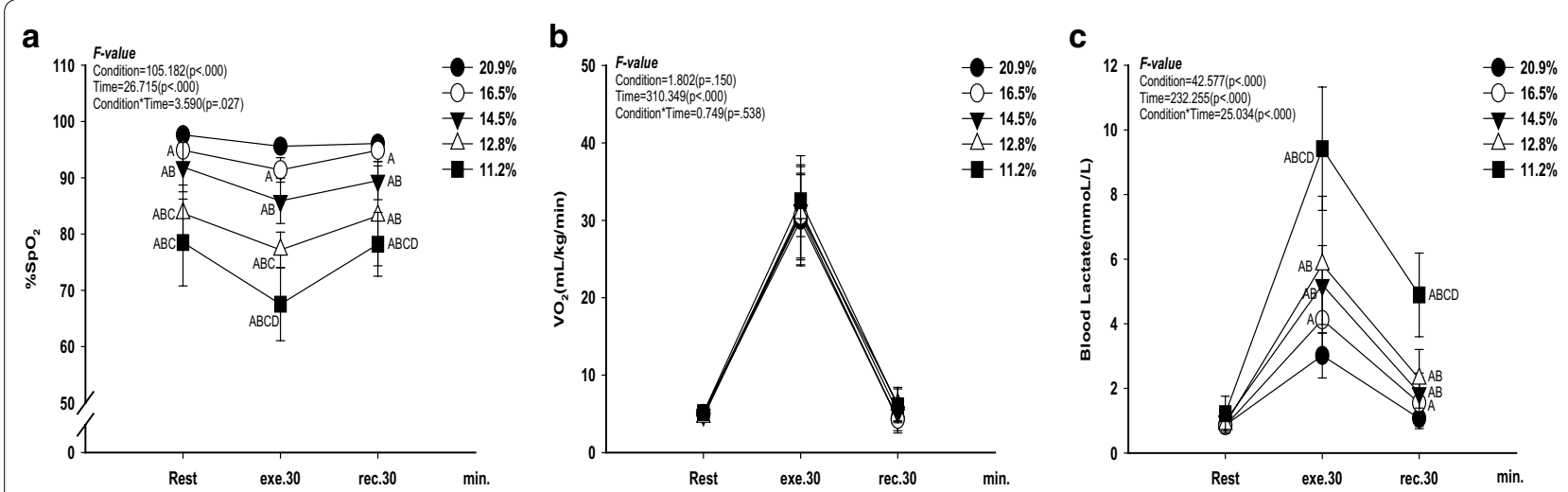

Fig. 1 Changes in metabolic parameters at rest, exercise time, and recovery time for all the conditions. a change in $\mathrm{S}_{\mathrm{p}} \mathrm{O}_{2}(\%)$. b change in VO $\mathrm{O}_{2}(\mathrm{~mL} /$ $\mathrm{kg} / \mathrm{min}$ ). c change in blood lactate level (mmol/L). The bars indicate the mean \pm S.D. ${ }^{A} p<.05$ vs. $20.9 \% \mathrm{O}_{2},{ }^{B} p<.05$ vs. $16.5 \% \mathrm{O}_{2},{ }^{C} p<.05$ vs. $14.5 \%$ $\mathrm{O}_{2}, \mathrm{D} p<.05$ vs. $12.8 \% \mathrm{O}_{2}$ 

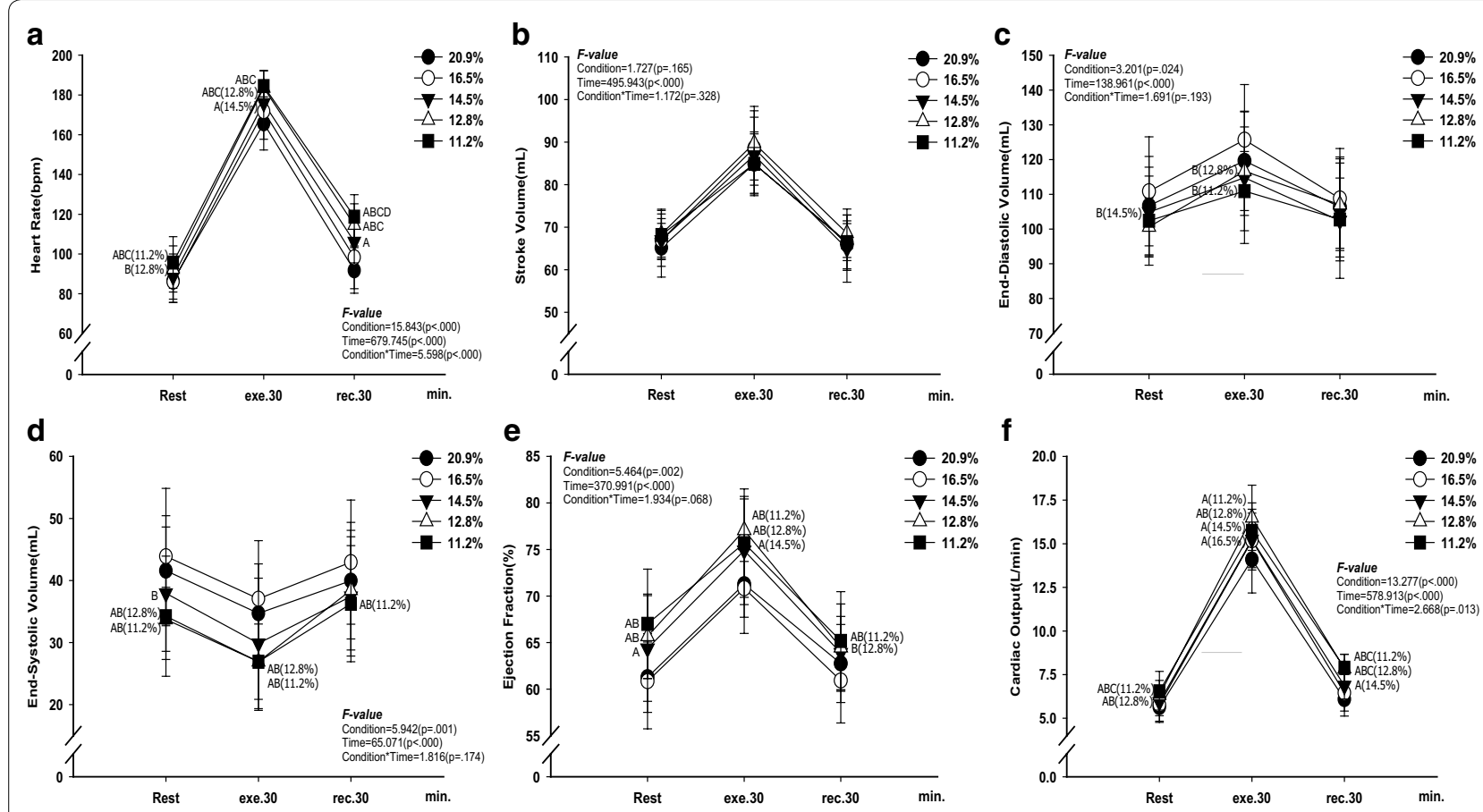

Fig. 2 Changes in cardiac function at rest, exercise time, and recovery time for all the conditions. a change in $\mathrm{HR}$ (bpm). b change in SV ( $\mathrm{mL}$ ). c change in EDV (mL). d change in ESV (mL). e change in EF (\%). f change in CO (L/min). The bars indicate the mean \pm S.D. ${ }^{A} p<.05$ vs. $20.9 \%$ O ${ }^{\mathrm{B}} p<.05$ vs. $16.5 \% \mathrm{O}_{2},{ }^{C} p<.05$ vs. $14.5 \% \mathrm{O}_{2},{ }^{\mathrm{D}} p<.05$ vs. $12.8 \% \mathrm{O}_{2}$

normobaric hypoxic conditions. In addition, HR, EF, and CO increased, but EDV, ESV decreased at oxygen partial pressures of $14.5 \% \mathrm{O}_{2}$ and below compared with 20.9 and $16.5 \% \mathrm{O}_{2}$ during exercise and recovery.

\section{Metabolic parameters}

Acute exposure to hypoxic conditions increases oxygen demand by lowering the capacity of the blood to transport oxygen and that of muscle to utilize oxygen, resulting in decrease in $\mathrm{VO}_{2}$ at the same relative intensity, as well as a decrease in $\mathrm{VO}_{2} \max$ (Lawler et al. 1988; Wehrlin and Hallén 2006). In our study, $\mathrm{S}_{\mathrm{p}} \mathrm{O}_{2}$ decreased as oxygen partial pressure decreased at rest, during exercise and recovery. However, we did not observe any significant differences in $\mathrm{VO}_{2}$ between sea-level and various hypoxic conditions during submaximal exercise and recovery, this is likely because the exercise intensity was fixed at constant level across simulated environment conditions resulting in the same amount of energy expenditure. Concordant with previous studies, increases in ventilation, breathing rate, $\mathrm{HR}$, and cardiac output adapted to acute hypoxic environments were possible without an increase in $\mathrm{VO}_{2}$ (Hill et al. 2011; Mazzeo 2008). In addition, our findings are consistent with those reported previously by Adamos et al. (2008) and Calbet et al. (2003).
These studies found no significant differences in $\mathrm{VO}_{2}$ during submaximal exercise between a simulated $5300 \mathrm{~m}$ hypoxic condition and sea level. The absence of an effect on $\mathrm{VO}_{2}$ may be explained by changes in cardiac function, specifically increases in $\mathrm{HR}, \mathrm{SV}$, and $\mathrm{CO}$ in response to reduced oxygen delivery and utilization capacities of the blood. Such changes in cardiac function were evident in our study group, and there were significant differences in HR, SV, ESV, and CO between sea level and the various hypoxic conditions.

In addition, blood lactate level increased as oxygen partial pressure decreased corresponding to increased levels in the present study. Under hypoxic conditions, decreased cardiometaboic levels (e.g. oxygen delivery, utilization of capacity of blood, and arterio-venous $\mathrm{O}_{2}$ difference) may result in an increase in the anaerobic energy metabolism contrast to decrease in the aerobic energy metabolism. For example, Adamos et al. (2008) reported that an increase in blood lactate level indicated the dependence of ATP resynthesize system on the anaerobic process. Additionally, decrease in oxygen delivery and utilizing capacities were associated with an increase in blood lactate level and led to increase in lactate production according to increase in lactate appearance and decrease in lactate disappearance during exercise (Park et al. 2016). 


\section{Cardiac function}

Our findings demonstrate that HR increased during exercise and recovery as the oxygen partial pressure decreased; however, $\mathrm{VO}_{2}$ did not change. Under hypoxic conditions, HR increases to compensate for the decrease in oxygen delivery and utilizing capacities, and the activated sympathetic nervous system (Holloway et al. 2011). A previous study showed that the sympathetic nervous system is activated by stimulation of afferent nerve in the metabolic receptor "Group IV" from accumulation of metabolites such as lactate and hydrogen ions (Sausen et al. 2009). Adamos et al. (2008) reported that HR increases by activation in the sympathetic nervous system and increased catecholamine level during exercise and recovery under hypoxic condition. Hainsworth and Drinkhill (2007)reported that activation of the sympathetic nervous system stimulates the release of catecholamine from the adrenal medulla under hypoxic conditions. Mazzeo (2008) stated that the stimulation of $\beta$-adrenaline receptors is a major factor responsible for the increase in HR during exercise under hypoxic conditions. Additionally, EDV and ESV are major factors affecting SV. A previous study reported that an increase in EDV and decrease in ESV could result in increases in ventricular contractility and SV (Hsu et al. 2006). In the present study, EDV increased at $12.8 \% \mathrm{O}_{2}$, and $11.2 \% \mathrm{O}_{2}$ compared with $16.5 \% \mathrm{O}_{2}$ during exercise. However, EDV showed no differences between hypoxic conditions and $20.9 \% \mathrm{O}_{2}$. ESV decreased at $12.8 \% \mathrm{O}_{2}$ and $11.2 \% \mathrm{O}_{2}$ compared with $20.9 \% \mathrm{O}_{2}$ during exercise. Therefore, compared with $20.9 \% \mathrm{O}_{2}$, EF (calculated as SV/EDV) increased in the oxygen partial pressure to $14.5 \% \mathrm{O}_{2}$ and below during exercise and increased in the oxygen partial pressure to $12.8 \% \mathrm{O}_{2}$ and below during recovery. These results may indicate that the activation of sympathetic nervous system and catecholamine level of the blood are triggered by increased calcium ions in cardiac muscle cells during exercise under hypoxic conditions (Mason 2000). However, in the present study, SV did not change between conditions. Also, this result might be explained by the reduction in left ventricular expansion capacity during exercise under hypoxic conditions (Fukuda et al. 2010). CO increased by HR during exercise and recovery as the oxygen partial pressure decreased. This is an acute compensation response for decrease in oxygen diffusion, delivery, and utilizing capacities in the lungs and muscle tissues (Naeije 2010).

\section{Conclusion}

A decrease in the oxygen partial pressure to $14.5 \% \mathrm{O}_{2}$ (3000 m normobaric hypoxic condition) and below might be associated with decreases in $\mathrm{S}_{\mathrm{p}} \mathrm{O}_{2}, \mathrm{EDV}, \mathrm{ESV}$ and increases in blood lactate level, $\mathrm{HR}, \mathrm{EF}$, and $\mathrm{CO}$ during submaximal exercise. These changes are an acute compensation response to reduced aerobic exercise capacity by decreased oxygen delivering and utilizing capacities under hypoxic conditions. However, a decrease in the oxygen partial pressure might not have an influence on SV.

\section{Limitation}

There are several limitations in the present study that should be noted. First, all participants were young healthy individuals, so a complete cross-section of the population was not represented. Second, the sample size was too small for sufficient power for some variables. Moreover, not all possible variables that might affect aerobic exercise capacity were investigated. A follow-up review with an increased sample size, including the same study design with the addition of other related factors is needed to further investigate the impact of high altitudes (hypoxic conditions) on exercise in relation to changes in various dependent variables.

\section{Authors' contributions}

All the authors contributing to this work have made the following declarations: HM, SS, and SN conceived and designed the experiments. HP and DL analyzed the data. Moon and Nam wrote the manuscript. Sunoo and Park reviewed the manuscript. All authors read and approved the final manuscript.

\section{Author details}

${ }^{1}$ Department of Sports and Outdoors, Eulji University, Yangji-dong, Sujeong-gu, Seongnam-si, Gyeonggi-do 461-713, Republic of Korea. ${ }^{2}$ Department of Sports Medicine, Kyunghee University, 1732, Deogyeong-daero, Giheung-gu, Yongin-si, Gyeonggi-do 17104, Republic of Korea. ${ }^{3}$ Performance Activity and Performance Institute, Konkuk University, Hwayang-dong, Gwangjin-gu, Seoul 143-701, Republic of Korea. ${ }^{4}$ Department of Physical Education, MyongJi University, Yongin Campus, Nam-dong, Cheoin-gu, Yongin-si, Gyeonggi-do 449-728, Republic of Korea.

\section{Competing interests}

The authors declare that they have no competing interests.

\section{Ethical considerations}

All procedures followed were in accordance with the ethical standards of the responsible committee on human experimentation (institutional and national) and with the Helsinki Declaration of 1975, as revised in 2008. Informed consent was obtained from all patients for being included in the study.

Received: 17 March 2016 Accepted: 29 July 2016

Published online: 08 August 2016

\footnotetext{
References

Adamos T, Papanikolaou Z, Voutselas V, Soulas D (2008) Effects of hypoxia on interval moderate exercise. J Biol Exerc 4:1-16

Bhaumik G, Dass D, Lama H, Chauhan SK (2008) Maximum exercise responses of men and women mountaineering trainees on induction to high altitude (4350 m) by trekking. Wilderness Environ Med 19(3):151-156

Brutsaert TD (2008) Do high-altitude natives have enhanced exercise performance at altitude? Appl Physiol Nutr Metab 33(3):582-592

Calbet JA, Boushel R, Rådegran G, Søndergaard H, Wagner PD, Saltin B (2003) Determinants of maximal oxygen uptake in severe acute hypoxia. Am J Physiol Regul Integr Comp Physiol 284(2):R291-303
} 
Charloux A, Lonsdorfer-Wolf E, Richard R, Lampert E, Oswald-Mammosser M, Mettauer B, Geny B, Lonsdorfer J (2000) A new impedance cardiograph device for the non-invasive evaluation of cardiac output at rest and during exercise: comparison with the "direct" Fick method. Eur J Appl Physiol 82(4):313-320

Elstad M, Nådland IH, Toska K, Walløe L (2009) Stroke volume decreases during mild dynamic and static exercise in supine humans. Acta Physiol (Oxf) 195(2):289-300

Friedmann B, Frese F, Menold E, Bärtsch P (2007) Effects of acute moderate hypoxia on anaerobic capacity in endurance-trained runners. Eur J Appl Physiol 101(1):67-73

Fukuda T, Maegawa T, Matsumoto A, Komatsu Y, Nakajima T, Nagai R, Kawahara $\mathrm{T}$ (2010) Effects of acute hypoxia at moderate altitude on stroke volume and cardiac output during exercise. Int Heart J 51(3):170-175

Hainsworth R, Drinkhill MJ (2007) Cardiovascular adjustments for life at high altitude. Respir Physiol Neurobiol 158(2):204-211

Hill NE, Stacey MJ, Woods DR (2011) Energy at high altitude. J R Army Med Corps 157(1):43-48

Hinckson EA, Hopkins WG, Downey BM, Smith TB (2006) The effect of intermittent hypoxic training via a hypoxic inhaler on physiological and performance measures in rowers: a pilot study. J Sci Med Sport 9(1):177-180

Holloway CJ, Montgomery HE, Murray AJ, Cochlin LE, Codreanu I, Hopwood N, Johnson AW, Rider OJ, Levett DZH, Tyler DJ, Francis JM, Neubauer S, Grocott MPW, Clarke K (2011) Cardiac response to hypobaric hypoxia: persistent change in cardiac mass, function, and energy metabolism after a trek to Mt Everest Base Camp. FASEB J 25(2):792-796

Hsu AR, Barnholt KE, Grundmann NK, Lin JH, McCallum SW, Friedlander AL (2006) Sildenafil improves cardiac output and exercise performance during acute hypoxia, but not normoxia. J Appl Physiol 100(6):2031-2040

Lawler J, Powers SK, Thompson D (1988) Linear relationship between $\mathrm{VO}_{2}$ max and $\mathrm{VO}_{2}$ max decrement during exposure to acute hypoxia. J Appl Physio 64(4):1486-1492

Mason NP (2000) The physiology of high altitude: an introduction to the cardio-respiratory changes occurring on ascent to altitude. Curr Anaesthesia Crit Care 11(1):34-41
Mazzeo RS (2008) Physiological responses to exercise at altitude: an update. Sports Med 38(1):1-8

Mazzeo RS, Bender PR, Brooks GA, Butterfield GE, Groves BM, Sutton JR, Wolfel $\mathrm{EE}$, Reeves JT (1991) Arterial catecholamine response during exercise with acute and chronic high-altitude exposure. Am J Physiol 261(4 Pt 1):E419-424

Miyashita M, Mutoh Y, Yoshika Y, Sadamoto T (1985) Effects of physical training. Med Sci Sports Exerc 1:3-5

Morton JP, Cable NT (2005) Effects of intermittent hypoxic training on aerobic and anaerobic performance. Ergonomics 48(11-14):1535-1546

Naeije R (2010) Physiological adaptation of the cardiovascular system to high altitude. Prog Cardiovasc Dis 52(6):456-466

Park HY, Hwang HJ, Park JH, Lee SN, Lim KW (2016) The effect of altitude/ hypoxic training on oxygen delivering capacity in elite athletes - a meta analysis. J Exerc Nutr Biochem 20(1):15-22

Robergs RA, Quintana R, Parker DL, Frankel CC (1998) Multiple variables explain the variability in the decrement in $\mathrm{VO}_{2}$ max during acute hypobaric hypoxia. Med Sci Sports Exerc 30(6):869-879

Sausen MT, Dalaney EP, Stillabower ME, Farquhar WB (2009) Enhanced metaboreflex sensitivity in hypertensive humans. Eur J Appl Physio 105(3):351-356

Sunoo S, Choi W, Lee K, Asano K, Mitsumori F (1997) P NMR study on energy metabolism in hindlimb muscle of the rats acclimatized to hypobaric condition. Japanese J Magn Reson Med 17:38-46

Thomson AJ, Drummond GB, Waring WS, Webb DJ, Maxwell SR (2006) Effects of short-term isocapnic hyperoxia and hypoxia on cardiovascular function. J Appl Physiol 101(3):809-816

Wehrlin JP, Hallén J (2006) Linear decrease in $\mathrm{VO}_{2}$ max and performance with increasing altitude in endurance athletes. Eur J Appl Physiol 96(4):404-412

Welsman J, Bywater K, Farr C, Welford D, Armstrong N (2005) Reliability of peak $\mathrm{VO}_{2}$ and maximal cardiac output assessed using thoracic bioimpedance in children. Eur J Appl Physiol 94:228-234

Yan B, Hu Y, Ji H, Bao D (2007) The effect of acute hypoxia on left ventricular function during exercise. Eur J Appl Physiol 100(3):261-265

\section{Submit your manuscript to a SpringerOpen ${ }^{\circ}$ journal and benefit from:}

- Convenient online submission

- Rigorous peer review

- Immediate publication on acceptance

- Open access: articles freely available online

- High visibility within the field

- Retaining the copyright to your article

Submit your next manuscript at springeropen.com 